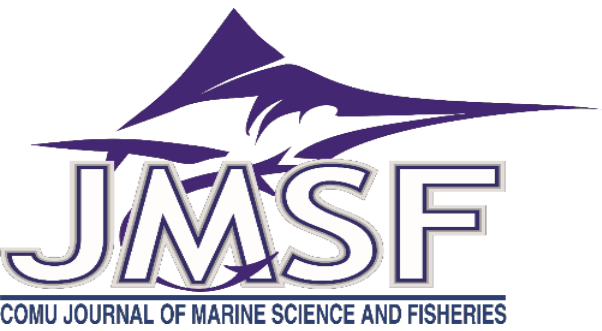

\title{
Determination of Interest Level of Amateur Seamanship in Çanakkale, Turkey
}

\author{
Ahmet Mazmanoğlu ${ }^{1 *}$, Uğur Altınağaç ${ }^{2}$ \\ 1* Canakkale Onsekiz Mart Üniversitesi Fen Bilimleri Enstitüsü Terzioğlu Yerleşkesi 17020 Merkez, Canakkale, Türkiye \\ ${ }^{2}$ Çanakkale Onsekiz Mart Üniversitesi Deniz Bilimleri ve Teknolojisi Fakültesi Terzioğlu Yerleşkesi 17020 Merkez, Çanakkale, \\ Türkiye \\ Correspondent: ahmet.mazmanoglu@uab.gov.tr \\ Received: 16.11.2020 Accepted: 10.12.2020 \\ Ahmet Mazmanoğlu: Orcid 0000-0003-3671-0525 \\ Ŭ̆ur Altınağaç: Orcid 0000-0002-3638-9834
}

How to cite this article: Mazmanoğlu, A. \& Altınağaç, U., (2020). Determination of interest level of amateur seamanship in Çanakkale, Turkey. COMU J. Mar. Sci. Fish, 3(2): 130-135. DOI: 10.46384/jmsf.826511

\begin{abstract}
In Turkey, Amateur Seaman Certificate (ADB) is a document issued by the Ministry of Transportation and Infrastructure as well as the Maritime Port Authority. In order to promote interest in amateur seamanship, maritime culture and seafaring life, a total of 1 million Amateur Seaman's Certificate will be issued to enthusiastic Turkish citizens by the Ministry of Transport and Infrastructure. In this study documentation and education processes which are important for the development of Amateur Seamanship were evaluated by conducting a survey in the city of Çanakkale. A questionnaire was applied to a total of 552 participants in order to determine the level of interest in seamanship by gender. Results indicated that men younger than 30 years with a high school diploma had the highest interest in seamanship. There was a statistically significant difference between genders in their interest in seamanship $(\mathrm{P} \leq 0,05)$
\end{abstract}

Keywords: Turkey, Maritime, Amateur Seamans Certificate, Education, Çanakkale, Transport and Infrastructure Ministry

\section{Çanakkale'de Amatör Denizciliğe İlgi Düzeyinin Tespiti}

Özet: Amatör Denizci belgesi (ADB), Türkiye’de Ulaştırma ve Altyapı Bakanlığı Denizcilik Genel Müdürlüğü ile tüm Liman Başkanlıkları tarafından verilen bir belgedir. Türkiye'de, insanımızın yüzünü denizlere çevirerek, amatör denizciliğin geliştirilmesi ve Türk halkına denizciliğin sevdirilmesi, özendirilmesi, denizcilik kültürünü aşılamak, denizci millet ve denizci ülke hedefine ulaşmak amacıyla, Ulaştırma ve Altyapı Bakanlığ tarafından 1 milyon Türkiye Cumhuriyeti vatandaşına, Amatör Denizci Belgesi verilmesi hedeflenmiştir. Bu çalışmada; Çanakkale örneği ile Amatör Denizciliğin gelişiminde önemli bir adım olan belgelendirme ve eğitim süreçleri, katılımcılara yapılan anketlerle değerlendirilmeye çalışılmıştır. Toplamda 522 kişi üzerinde uygulanan anketler ile cinsiyet durumuna göre kişilerin denizciliğe olan ilgi düzeylerinin belirlenmesi hedeflenmiştir. Anketler sonucunda katılımcıların en fazla 30'lu yaşlarda, lise mezunu ve erkek bireyler olduğu görülmüştür. Cinsiyet ayrımına göre yapılan istatistiksel analiz sonucunda denize ve denizciliğe olan ilgileri arasındaki fark önemli bulunmuştur $(\mathrm{P} \leq 0,05)$.

Anahtar Kelimeler: Türkiye, Denizcilik, Amatör Denizci Belgesi, Eğitim, Çanakkale, Ulaştırma ve Altyapı Bakanlığ1

Giriş

Türkiye'de balıkçılık sektörü de dahil olmak üzere tekne ile faaliyet yapabilmek için T.C. Ulaştırma ve
Altyapı Bakanlığı tarafından verilmiş bir yeterlilik belgesine haiz olmak gerekmektedir (Baş ve 
Deniz,1996). Bu kapsamda uluslararası standarda sahip yeterlilik belgeleri ile birlikte yerel otoritelerin verdiğ $\mathrm{i}$ bölgesel nitelikte geçerli olan yeterlilik belgeleri de mevcuttur. Uluslararası standarda sahip yeterlilik belgeleri, eğitim süreleri ve müfredatları da dahil olmak üzere Standard Training and Certificate of Watchkeeping adlı konvansiyon kurallarında açıkça belirtilmiştir (IMO, 2019). Bu kurallar bütününde belirtilen yeterlilik belgelerinin eğitim süreleri, müfredatı ve yenileme işlemleri, ticari faaliyetleri kapsadı ̆̆ından daha ağır şartlara sahiptir.

Ancak yerel otoriteler ticari faaliyetler dışında sportif amaçlı kullanılmak üzere bazı yeterlilikler verebilmektedir. Türkiye'de denizcilik otoritesi olan T.C. Ulaştırma ve Altyapı Bakanlığı da geçerlilik çerçevesi belirlenmiş, Amatör Denizci Belgesi adı altında bir yeterlilik belgesi vermektedir. Tam boyu 24 metreden küçük olan ve ticari faaliyette bulunmayan teknelerde geçerli olan bu yeterlilik belgesi için otorite tarafından 2018 yılı itibarıyla 1 Milyon Amatör Denizci adı altında bir proje yürütmektedir (UAB, 2018). Bu proje kapsamında ilgili yeterlilik, eğitim semineri ve seminer sonu uygulanan sınavda başarılı olanlara verilmektedir.

Denizcilik müsteşarlığı tarafından 2009 yılına kadar sinavla verilen bu belge (Anonim, 1982), daha sonra denizcilik federasyonu tarafindan online sinav yapılmak suretiyle denize ilgisi olan kişilere verilmekteydi (Süzgen ve Akten, 1985; Atmaca, 2005). Bugün yine bakanlık bünyesinde sinavla verilen bu belge ile kişiler şahsa ait 24 metreye kadar uzunlukta tekneleri kullanabilmektedir (Anonim, 1958).

Çalışma kapsamında özellikle denize kıyısı olan bölgelerde olmakla birlikte denize kıyısı olmayan bölgelerdeki halkın deniz ve denizcilik ile etkileşimini arttırmak amacıyla öncelikle kamu spotu programları ile halka amatör denizci olabilmeleri için ne yapmaları gerektiği konusunda bakanlık tarafından gerekli bilgilendirmeler yapılmıştır. Bilgilendirme sonrası açılan kursların yer ve saatleri duyurularak katılımcıların bu kurslara iştiraki sağlanmıştır. Kurs kapsamında, amatör denizciliğin ne olduğu, nasıl yapılması gerektiği ve teknik denizci terimleri, hesaplamalar, yön bulma vs. gibi konularda katılımcılara eğitimler verilmiştir. Eğitim sonrasında katılımcılara amatör denizci belgesi verilebilmesi amaciyla kursta verilen konulardan sinav yapılarak en az 60 puan almaları istenmiş, 60 ve üzeri puan alanlara amatör denizci belgesi verilmiş ve verilmeye devam edilmektedir.

Yapılan bu çalışma sonrasında bakanlığın hedefi, üç tarafı denizlerle çevrili ülkemizdeki insanların sosyo-ekonomik ve sosyo-kültürel açıdan toplumun deniz ile bağını arttırarak amatör balıkçı, amatör denizci ve denizle buluşan insan sayısını, bir milyon kişiye ulaştırmaktır. Günümüze kadar verilen 'Amatör
Denizci Belgesi' sayısının 650 bine yaklaştığı yetkili otoriteler tarafından bildirilmiştir (UAB, 2019 a).

Türkiye'de 2019 yllına ait istatistiğe göre Çanakkale'ye bağlı 2909 kayıtlı tekne bulunmaktadır (UAB, 2019 b). Bu teknelerin 725 tanesi ticari faaliyette bulunmayan ve tam boyu 24 metreden küçük teknelerdir. $\mathrm{Bu}$ kapsamda Çanakkale'de amatör denizci belgesi ile kullanılabilen 725 adet tekne bulunmasına rağmen 2020 Ekim ayı itibarıyla yaklaşık 24000 kişi amatör denizci belgesi almıştır (UAB, 2020). Bu da amatör denizci belgesine, talebin ne kadar yoğun olduğunun bir kanıtı olarak karşımıza ç1kmaktadır. Çanakkale gibi denizciliğin sosyal hayata entegre olduğu bir bölgede talebin aratarak devam edeceği kaçınılmaz bir gerçektir.

$\mathrm{Bu}$ araştırmada, Çanakkale bölgesinde amatör denizciliğgin gelişimi izlenerek, projenin verimliliğinin incelenmesi amaçlanmış ve anket uygulanan kişilerin denize ve denizciliğe olan ilgileri araştırılmıştır. Şimdiye kadar gelinen nokta ve daha ilerisi için projenin etkileri değerlendirilmiş, böylece 2020 yılı itibarıyla amatör denizci belgesine sahip kişi sayısı ve talep yoğunluğunun bölgesel fayda ve zararı irdelenmiştir.

\section{Materyal ve Metot}

Türkiye'de denizciliği sadece ticari faaliyet olarak görmeyip sportif ve hobi amaçlı denize çıkan insanların bu belgeye bakışı anketlerle araştırılmıştır. Bunun haricinde denizciliği amatör olarak yapan ve daha ilerisinde profesyonel olarak belge almayı düşünenler ankette belirlenmeye çalışılmıştır.

Bu kapsamda Çanakkale ilinde T.C. Ulaştırma ve Altyapı Bakanlığı tarafindan aylık bazda düzenlenen, amatör denizci eğitimi ve bu eğitim sonunda yapılan sınavlara katılan amatör denizci belgesi alınmasıyla ilgili gerekli şartları sağlayan kişilere, anketler uygulanmıştır. Bu bağlamda amatör denizci belgesi almak için başvuru yapanlar arasında \%98 güven aralığında \%5 kabul edilebilir hata düzeyinde, şu ana kadar Çanakkale ilinde bu belgeyi alan 24000 kişilik ana kütleden 522 birimlik örneklem büyüklüğü üzerinden anket uygulanmıştır. Bu belgeye sahip olma amaçlarından, sahip olduktan sonra yapacaklarına kadar ilgili sorular yöneltilmiştir. Yürütülen bu çalışmalar, Amatör Denizciliğin gelişimindeki değişiklikler, hedeflenen kitle, istatistikler, ulaşılan nokta ve ayrica bu belgenin verilmesindeki olumlu ve olumsuz yönler Çanakkale örneği ile tartışılmıştır. Amatör denizciliğin son yıllar içerisindeki gelişimi ve belge almak için başvuran kişilerin denizcilikle olan ilgi düzeyleri belirlenmiştir.

Ankette kişilere yöneltilen sorular aşağıda verilmiştir.

1-Ailenizde Denizde çalışan var mı?

2-Yüzme biliyor musunuz?

3-Daha önce sportif veya gezi amaçlı denize çıktınız mı? 
4-Şahsınıza ait tekneniz var mı?

5-Herhangi bir tekneniz yoksa Tekne edinme fikriniz var mi?

6-Daha önce hiç tekne ya da motorlu bir deniz aracı kullandınız mi?

7-Daha önce denizcilikle ilgili herhangi bir yeterlilik belgesi aldınız mi?

8-Verilen eğitimi yeterli buluyor musunuz?

9-Eğitime ulaşmada herhangi bir zorluk yaşadınız $\mathrm{m} 1$ ?

10-Denizcilikle alakalı haberleri takip ediyor musunuz?

11-Eğitimin faydalı olduğunu düşünüyor musunuz?

12-İleride ticari faaliyetlerde bulunmak için başka bir gemi adamı yeterliliği almayı düşünüyor musunuz?

13-Çevrenizdeki kişileri ADB eğitimine katılmaları konusunda yönlendiriyor musunuz?

14-Eğitim Periyotlarının sıklığından memnun musunuz?

15-Eğitim programında uygulamalı dersler olmasını ister misiniz?

16-ADB eğitimi kolaylaştırılmasa yine de bu belgeyi almayı düşünür müsünüz?

17-Belgeyi aldıktan sonra düzenli olarak denize çıkmayı düşünüyor musunuz?

18-Bu eğitim denize olan ilginizi artırdı mı?
19-Bu eğitimden sonra motorlu bir deniz aracını kullanacak beceri, yetenek ve cesareti kendinizde görüyor musunuz?

Çalışmada Yöntem olarak kişilere yazılı anket uygulanmış, Anket uygulanan kişiler basit tesadüfi örnekleme yöntemiyle seçilmiștir. Anketteki değişiklikleri ölçme yöntemi olarak sorulara verilen yanıtlar için çift mukayese ölçeği ("Evet" / "Hayır") kullanılmıştır (Arıkan, 2018). Ankete katılan kişilerin cinsiyet durumlarına göre denizcilik ile olan ilişkileri, her soru için ki kare bağımsızlık testi ile analiz edilmiştir.

\section{Bulgular}

Ankete katılan kişilerin demografik yapıları incelenmiş olup, yaş, cinsiyet ve eğitim durumlarına ait bilgiler aşağıdaki grafiklerde verilmiştir. Anket uygulanan kişilerin yaş ortalamasının 36-37 olduğu, En fazla katılımın ise 30'lu yaşlarda sağlandığı görülmektedir (Şekil 1).

Katılımcıların eğitim durumlarına bakıldığında ise \%34 oranında en fazla lise mezunu kişilerden oluştuğu görülmüştür (Şekil 2). Eğitime katılım sağlayanları cinsiyet olarak ayırdığımızda en fazla, erkeklerin bu belgeye rağbet gösterdiği söylenebilir (Şekil 3).

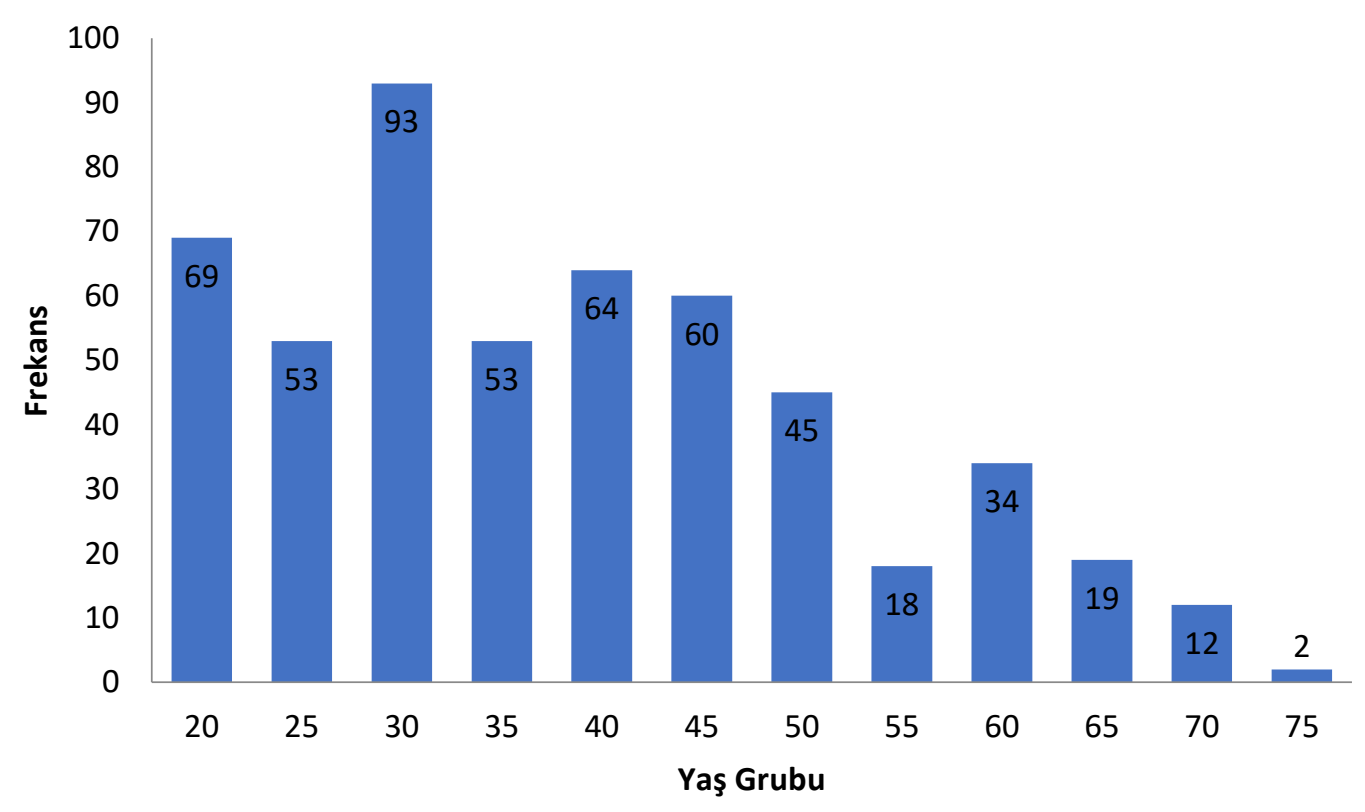

Şekil 1. Katılımcıların Yaş Frekans Grafiği 


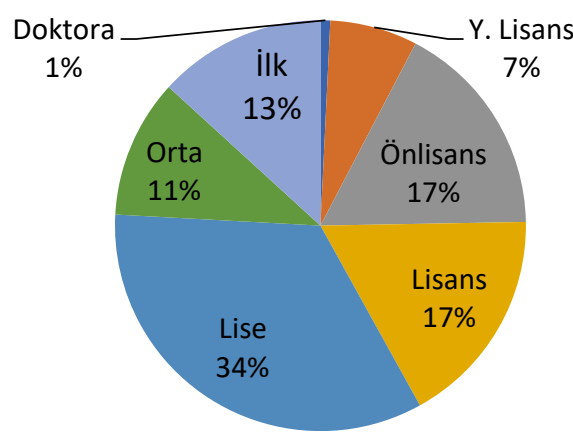

Şekil 2. Katılımcıların Eğitim Durumu

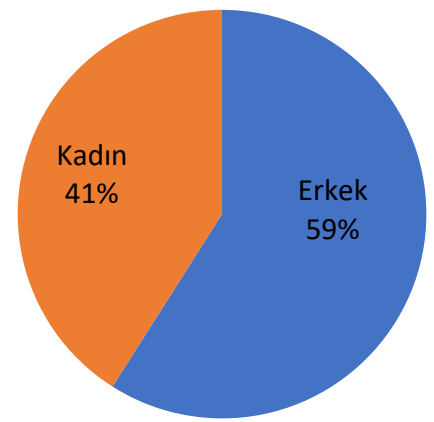

Şekil 3. Katılımcıların Cinsiyet Durumu

Çalışma kapsamında katılımcılara yöneltilen soruların cevapları, yüzde olarak aşağıda verilmiştir.

1-Ailenizde Denizde çalışan var mı? Sorusuna $\% 46$ evet \%54 hayır cevabı alınmıştır. Buna göre anket yapılanların yarısına yakınının denizde bir çalışanı olduğu anlaşılmaktadır.

2-Yüzme biliyor musunuz? Sorusuna \%73 evet \%27 hayır cevabı alınmıştır. Ankete katılanların çoğunluğunun denizle olan ilişkisinin yüzme bilmek olduğu, aslında sınava katılan kişilerin bu bağlamda denizle çokta ilgisiz olmadığı anlaşılmaktadır.

3-Daha önce sportif veya gezi amaçlı denize çıktınız mı? Sorusuna $\% 57$ evet $\% 43$ hayır cevabı alınmıştır. Bu sonuca göre ankete katılanların yarısından fazlasının bir deniz aracıyla tanıştığı sonucu çıkarılmaktadır.

4-Şahsınıza ait tekneniz var mı? Sorusuna \%22 evet \%78 hayır cevabı alınmıştır. Ankete katılan kişilerin bazılarının eş olması sebebiyle kendilerine ait teknenin aslında, aileye ait tekne olmasından dolay 1 hem kadın hem erkek bu soruya evet cevabı verdiği için, tekne sahibi olan kişi sayısı \%22 den daha azdır.

5-Herhangi bir tekneniz yoksa Tekne edinme fikriniz var mı? Sorusuna $\% 56$ evet $\% 44$ hayır cevab1 alınmıştır. $\mathrm{Bu}$ sonuca göre ankete katılan kişilerin çoğunluğun kafasında bir deniz aracı edinme fikri olduğu anlaşılmaktadır.

6-Daha önce hiç tekne ya da motorlu bir deniz aracı kullandınız mı? Sorusuna $\% 47$ evet $\% 53$ hayır cevabı alınması katılımcıların yarısına yakın oranda kişinin daha önce bir deniz aracı kullanmış olduğunu ifade etmektedir.

7-Daha önce denizcilikle ilgili herhangi bir yeterlilik belgesi aldınız mı? Sorusuna $\% 34$ evet $\% 66$ hayır cevabı alınmıştır.

8-Verilen eğitimi yeterli buluyor musunuz? Sorusuna $\% 48$ evet $\% 52$ hayır cevab1 alınmıştır. Ankete katılanların yarısından çoğu verilen eğitimin pratik eğitimle desteklenmesi gerektiğini düşünmektedir.

9-Eğitime ulaşmada herhangi bir zorluk yaşadınız mı? Sorusuna $\% 39$ evet $\% 61$ hayır cevabı alınmıştır.

10-Denizcilikle alakalı haberleri takip ediyor musunuz? Sorusuna $\% 49$ evet $\% 51$ hayır cevabı alınmıştır.

11-Eğitimin faydalı olduğunu düşünüyor musunuz? Sorusuna $\% 84$ evet $\% 16$ hayır cevab1 alınmıştır. Ankete katılanların çoğunluğu eğitimin başarılı olduğunu düşünmektedir.

12-İleride ticari faaliyetlerde bulunmak için başka bir gemi adamı yeterliliği almayı düşünüyor musunuz? Sorusuna $\% 48$ evet $\% 52$ hayır cevabı alınmıştır.

13-Çevrenizdeki kişileri ADB eğitimine katılmaları konusunda yönlendiriyor musunuz? Sorusuna $\% 68$ evet $\% 32$ hayır cevabı alınmıştır.

14-Eğitim Periyotlarının sıklğıından memnun musunuz? Sorusuna $\% 53$ evet $\% 47$ hayır cevabı alınmıştır.

15-Eğitim programında uygulamalı dersler olmasını ister misiniz? Sorusuna $\% 76$ evet $\% 24$ hayır cevabı alınmıştır. Bu da eğitimlerin uygulamalı olması gerekliliğinin katılımcılar tarafından çoğunlukla istendiğini göstermektedir.

16-ADB eğitimi kolaylaştırılmasa yine de bu belgeyi almayı düşünür müsünüz? Sorusuna $\% 60$ evet \%40 hayır cevabı alınmıştır.

17-Belgeyi aldıktan sonra düzenli olarak denize çıkmayı düşünüyor musunuz? Sorusuna $\% 52$ evet \%48 hayır cevabı alınmıştır.

18-Bu eğitim denize olan ilginizi artırdı mı? Sorusuna $\% 67$ evet $\% 33$ hayır cevabı alınmıştır.

19-Bu eğitimden sonra motorlu bir deniz aracını kullanacak beceri, yetenek ve cesareti kendinizde görüyor musunuz? Sorusuna $\% 54$ evet $\% 46$ hayır cevabı alınmıştır.

Çalışmada katılımcıların cinsiyet durumuna göre denizcilik ile olan ilişkileri açısından her soru, ki-kare bağımsızlık testi ile analiz edilmiştir. Birinci ve beşinci sorular hariç katılımcıların erkek ya da kadın olmaları ile denize ve denizciliğe olan ilgileri arasındaki fark önemli bulunmuştur $(\mathrm{P} \leq 0,05)$. 


\section{Tartışma}

Bir ülkede deniz politikasının doğru tesis edilmesi ve uygulanmasında son adım geri besleme yapılmasıdır. $\mathrm{Bu}$ amaçla uygulanabilecek yöntemlerden biri de anket uygulanmasıdır. Yetkili otorite tarafından denizcilik politikalarının uygunluğunun test edilmesine yönelik olarak yaptırılacak anketler sayesinde hem halkın denizciliğe ilgisi artırılmış hem de hükümetin denizcilik politikalarına kamuoyu desteği sağlanmış olur. Bu kapsamda, hedef kitle olan genç nüfusu denizci olarak yetiştirmeye yönelik denizcilik politikaları belirleyerek uygulamaktır. (Çetin, 2009). T.C. Ulaştırma ve Altyapı Bakanlığı tarafından yürütülen 1 Milyon Amatör Denizci projesi kapsamında; verilen kurslar ve yapılan sınavlar ile amatör denizci sayısı gün geçtikçe artmaktadır.

Bir ulusun sahip olduğu denizcilik gücü o ulusun sahip olduğu ulusal gücün bir alt bölümü olarak anlaşılmalıdır. Çünkü denizcilik gücü; bir ulusun denize ve denizciliğe ilişkin, olanak ve yeteneklerinin, ulusal çıkarlar yararına değerlendirilebilmesi, kullanılması, korunması amacıyla harcanan çabaların insan gücü, coğrafya, sosyoloji, psikososyoloji, teknoloji, ekonomi ve askeri güç alanlarında oluşturduğu etkinliklerdir (Göksel, 2011).

Amatör Denizci Belgesi sahibi olacak kişilerin 10 BHP (Beygir gücü) üzeri tekne almak istemeleri durumunda, yerli tekne üreticileri, olta malzemesi satanlar, tekne yedek parçası ve donanımı satanlar, tekne bakım ve onarımı yapanlar, teknelerin bağlanması gereken marinalar bu işten dolaylı olarak kazanç sağlamaktadırlar. Amatör Denizcilerin artması sosyokültürel açıdan insanların keyifli zaman geçirmesini sağlamaktadır. Bireyler stresten kurtuldukça, toplumsal huzur ve güven ortamı sağlamak kolaylaşacaktır. Yaşam kalitesini arttıran tüm aktiviteler, gelişmiş toplumlarda benzer şekilde desteklenmektedir. Bu şekilde sekiz bin kilometrenin üstünde olan deniz kıyılarımızdan çok daha fazla istifade edilecektir. (Altınok ve Ersoy, 1995).

Yapılan anketlerde, ailesinde denizci olmamasına rağmen amatör denizci belgesi eğitimine katılanların sayısal olarak fazlalığı göze çarpmaktadır. Bununla beraber yüzme bilenlerin sayısı ile denizi tanıdıkları ve aşina oldukları yorumu yapılabilmektedir. Denizlerde ticari faaliyette bulunacak kişiler için yeterlilikler 1978 STCW Konvansiyonu ile belirlenmiştir (IMO, 2019). Bu eğitimlerin büyük bir bölümü uygulama içermektedir. Proje kapsamında, eğitimlerde uygulama yapılamadığı için tekne almayı düşünen kişiler uygulamalı eğitimleri kendileri yapmak zorunda kalacaklardır. Üçüncü soruda \%43 gibi yarıya yakın bir katılımcı grubunun, daha önce bir deniz aracıyla hiç denize çıkmamış olması, tekne almak ister misiniz sorusuna ise $\% 56$ evet cevabının verilmesi, bu kișiler için, deniz üzerinde sıkıntı olușturabilecek durumlardan bir tanesidir.
Katılımcıların büyük bir çoğunluğunun denizcilikle ilgili daha önce herhangi bir yeterliliğinin olmadığı görülmektedir. Bu da amatör denizci belgesi ile ilk defa denize çıkacaklarını göstermektedir. Ancak eğitim süresinin yeterli olmadığı konusunda bir fikir birliği vardır diyebiliriz. Burada en önemli sorulardan bir tanesi olan "bu eğitimin faydalı olduğunu düşünüyor musunuz? sorusuna $\% 84$ civarında olumlu yanıt gelmiştir. Şahsına ait tekne olmamasına rağmen belge almaya gelenlerin sayısındaki fazlalık göze çarpmaktadır.

Eğitime başvuru kısmında eski katılımcıların, yeni kişileri yönlendirdiği anket içerisinde belirtilmiştir. Bu da projenin duyurulması konusunda oldukça önemli bir veri olarak karşımıza çıkmıştır. İnsanların denize ilgisini artıran amatör denizci belgesi ile düzenli bir şekilde denize çıkacaklarını söyleyenlerin sayısındaki çokluk ise projenin amacına uygun yürüdüğünü göstermektedir. Anketin en önemli sorularından biri olan "bu eğitimden sonra motorlu bir deniz aracını kullanacak beceri, yetenek ve cesareti kendinizde görüyor musunuz?" Sorusuna \%46 düzeyinde hayır cevabı gelmiştir. Buda bize bu belgeyi alan kişilerin, uygulama eğitimi olmadan denize çıkamayacaklarını ifade etmektedir. Nitekim "Eğitim programında uygulamalı dersler olmasını ister misiniz?" sorusuna verilen $\% 76$ evet cevabı bu projenin ileri safhalarında, insanları denizci yapabilmek için, uygulamalı eğitimlerin mutlak olması gerektiğini bize ifade etmektedir.

Amatör Denizci eğitimlerinin ve belge alınması konusunda, denize olan ilgilerini araştırmak amaciyla yapılan bu çalışmada, katılımcılara uygulanan anketler göstermiştir ki, Çanakkale bölgesinde bu yeterliliğe talebin çok yoğun, eğitimlerin faydalı ve kişilere denizciliği sevdirme konusunda başarılı bir uygulama olduğu söylenebilir. Ayrıca son 20 yıl içerisinde şu ana kadar 207 bin kişinin, Amatör Denizci Belgesi aldığı, fakat bu projeden sonra eğitime katılan ve belge alan kişi sayısının son 2 yılda 522 bin kişi olması projenin başarılı olduğunun bir göstergesidir (Anonim, 2020). Ancak bu eğitimlerin uygulamalı olması durumunda ileride deniz üzerinde yaşanacak sıkıntılar azaltılmış olacaktır.

Ulaştırma ve Altyapı Bakanlığı'nın yapmış olduğu çalışmalar ve bu araştırma sonuçlarına göre, insanların denize olan ilgisinin yeterli olmadığı, denizi sevseler bile gerekli olmadıkça denizcilikle olan ilişkilerini sınırlı tuttukları gözlemlenmiştir. Yapılacak bu ve buna benzer projeler ile deniz ve denizciliğin sevdirilmesi, denizciliğe ilgi duymasına karşın yeterli bilgi ve amatör denizci belgesi olmadığından dolayı denizcilikle uğraşamayan kişilere, amatör denizci belgesi ve eğitimi verilmesi denizciliğimizin sevdirilmesi yönünde olumlu bir katkı olacaktır. 


\section{Teşekkür}

$\mathrm{Bu}$ araştırma, Ahmet Mazmanoğlu'nun Yüksek Lisans Tez çalışmasının bir bölümüdür. Desteklerinden dolayı Çanakkale Liman Başkanlığına ve ÇOMÜ Fen Edebiyat Fakültesi İstatistik bölümü Dr. Öğretim Üyesi Burcu Mestav’a teşekkür ederiz.

\section{Kaynaklar}

Altınok, Y., Ersoy Ş. (1995). Türkiye Kıyıları ve Yakın Çevresini Etkileyen Tsunamiler. İstanbul (Cilt:9) 1s.

Anonim, (1958). Gemi Sevk ve İdaresi. DZ.K.K. Eğitim Yayınları, İstanbul.

Anonim, (1982). Amatör Denizcilere Sinav Kılavuzu, Deniz Kuvvetlerini Güçlendirme Vakfı, İstanbul, 1982.

Anonim, (2020). Ulaştırma ve Altyap1 Bakanlığ1, https://denizcilik.uab.gov.tr/haberler/amatordenizci-belgesi-ve-kisa-mesafe-telsiz-operatoruegitim-ve-sinav-basvuru-sistemi-kullanima-acildi

Arıkan, R. (2018). Anket Yöntemi Üzerinde Bir Değerlendirme. Haliç Üniversitesi Sosyal Bilimler Dergisi 2018, 1: 97-159

Atmaca, S. (2005). Amatör Denizci Elkitabı. Amatör Denizcilik Federasyonu, Yeşilyurt, Bakırköy, İstanbul (16. Bask1) 274s.

Baş, M., Deniz, C. (1996). Amatör Denizcilik. İstanbul.

Çetin, O., (2009). Denizcilik Sektöründe Mukayeseli Bir Model. Güvenlik Stratejileri Dergisi, 5(10), Retrieved from https://dergipark.org.tr/tr/ pub/guvenlikstrtj/issue/7533/99198

Göksel, A., M. (2011). Türkiye'de Denizcilik Bilinci. Boatbuilder Türkiye Dergisi sayı:29.

IMO (2019). International Convention on Standards of Training, Certification and Watchkeeping for Seafarers (STCW). https://www.imo.org/en/ OurWork/HumanElement/Pages/STCW-ConvLINK.aspx

Süzgen, Y., Akten, N. (1985). Denizcinin Kılavuzu. İstanbul.

UAB, (2018). Ulaştırma ve Altyapı Bakanlığ 1 , https://www.uab.gov.tr/haberler/hedef-2023-te-1milyon-amator-denizci

UAB, (2019a). Ulaştırma ve Altyapı Bakanlığı. https://www.uab.gov.tr/basin-aciklamalari /amator - denizcilikte-1-milyon-hedefine-geri-sayim

UAB, (2019b). Ulaştırma ve Altyapı Bakanlığı edenizcilik bağlama kütüğü bilgi sistemi 2019

UAB, (2020). Ulaştırma ve Altyapı Bakanlığı Amatör denizci bilgi sistemi 2020. 